\title{
Leachate Characterization and Assessment of Surface Water Quality near Karadiyana Solid Waste Dump Site
}

\author{
Mandakini L.L.U. ${ }^{1 *}$, Mannapperuma N. ${ }^{1}$, Bandara N.J.G.J. ${ }^{2}$, Silva K.D.C.C.J. ${ }^{1}$ and \\ Perera M.T.C. ${ }^{2}$
}

${ }^{1}$ Waste Management Authority (Western Province), Sri Lanka

${ }^{2}$ Center for Sustainability, Department of Forestry and Environmental Science, University of Sri Jayewardenepura, Sri Lanka

*upekhamandakini@gmail.com

\begin{abstract}
Leachate generation is one of the major issues associated with open dumping of solid waste. In Sri Lanka, the most common practice of municipal solid waste handling is open dumping and the leachate generated from these sites create serious environmental and social problems. Therefore leachate should be treated before been discharged to the environment. When developing a sustainable leachate treatment strategy, leachate characterization is important in order to identify critical contaminants.
\end{abstract}

Karadiyana solid waste dump site which is located in the Western Province is the second largest dumpsite in Sri Lanka. It receives 550 MT of solid waste daily from 7 local authorities in Colombo district. As this dumpsite is located in a highly urbanized and environmentally sensitive area which is adjacent to the Bolgoda river in Piliyandala it is essential to take measures to prevent adverse impacts of leachate. Therefore this monitoring study was carried out to identify the characteristics of leachate.

Leachate samples and surface water were collected from 7 locations around the site for 10 months. Analysis was done on temperature, $\mathrm{pH}$, conductivity, TDS, $\mathrm{NO}_{3}{ }^{-}, \mathrm{BOD}, \mathrm{COD}$, and heavy metals i.e. $\mathrm{Cr}, \mathrm{Zn}, \mathrm{Cd}, \mathrm{Pb}$ and Ni.

According to the results temperature, $\mathrm{pH}$ and concentrations of $\mathrm{NO}_{3}{ }^{-}, \mathrm{Cr}, \mathrm{Zn}, \mathrm{Cd}, \mathrm{Pb}$ and $\mathrm{Ni}$ of all sampling locations were within the permeable levels of Sri Lankan standards. Heavy metal concentrations are very low which may be because this dump site only is not accepting industrial waste. However the conductivity, TDS, BOD and COD levels of all the locations have exceeded the tolerance limits significantly due to the municipal solid waste which consist of large portion of organic waste. Furthermore all the parameters are higher in leachate samples than surface water samples. This study reveals that an applicable leachate treatment system should be introduced in order to reduce BOD and COD levels.

Keywords: Karadiyana dump site, Leachate, Solid waste

Proceedings of the International Forestry and Environment Symposium 2016, Department of Forestry and Environmental Science, University of Sri Jayewardenepura, Sri Lanka. 